\title{
Extracorporeal membrane oxygenation after protracted ventricular fibrillation cardiac arrest: case report and discussion
}

\author{
Riyad B. Abu-Laban, MD, MHSc*; David Migneault, MDCM*; Meghan R. Grant, MDCM*; \\ Vinay Dhingra, $\mathrm{MD}^{\dagger}$; Anthony Fung, MB, BS ${ }^{\ddagger}$; Richard C. Cook, MD ; David Sweet, $\mathrm{MD}^{*^{\dagger}}$
}

\section{ABSTRACT}

Extracorporeal membrane oxygenation (ECMO) is a method to provide temporary cardiac and respiratory support to critically ill patients. In recent years, the role of ECMO in emergency departments (EDs) for select adults has increased. We present the dramatic case of a 29 -year-old man who was placed on venoarterial ECMO for cardiogenic shock and respiratory failure following collapse and protracted ventricular fibrillation cardiac arrest in our ED. Resuscitation efforts prior to ECMO commencement included 49 minutes of virtually continuous cardiopulmonary resuscitation (CPR), 11 defibrillations, administration of numerous medications, including a thrombolytic agent, while CPR was ongoing, percutaneous coronary intervention and stenting for a mid-left anterior descending coronary artery dissection and thrombotic occlusion, inotropic support, and intra-aortic balloon pump counterpulsation. Over the next 48 hours following ECMO commencement, the patient's cardiorespiratory function rapidly improved, and he was discharged home 9 days after admission with no neurologic sequelae. The history, indications, and increasing role of ECMO in a range of conditions, including cardiac arrest, are reviewed.

\section{RÉSUMÉ}

L'oxygénation extracorporelle sur oxygénateur à membrane (OEOM) est un moyen de fournir une assistance cardiaque et respiratoire temporaire à des patients gravement malades. Le rôle de I'OEOM a gagné du terrain chez certains adultes aux services des urgences (SU) au cours des dernières années. Sera exposé ici le cas spectaculaire d'un homme de 29 ans, soumis à I'OEOM veino-artérielle pour un choc cardiogénique et une insuffisance respiratoire suivant un collapsus et un arrêt cardiaque causé par un accès prolongé de fibrillation ventriculaire, qui est survenu au SU de I'hôpital. Les moyens de réanimation mis en œuvre avant le début de I'OEOM comprenaient des manœuvres de réanimation cardiorespiratoire ( $R C R$ ) pratiquées de façon quasi continue durant 49 minutes; 11 tentatives de défibrillation; I'administration de nombreux médicaments, dont un thrombolytique, pendant que se poursuivaient les manœuvres de RCR; une intervention coronarienne percutanée et la pose d'une endoprothèse pour une dissection du segment moyen de l'artère interventriculaire antérieure et une oblitération thrombotique; un soutien inotrope et la contrepulsion par ballon intra-aortique. Au cours des 48 heures suivant le début de I'OEOM, l'état cardiorespiratoire du patient s'est amélioré rapidement, et celui-ci est retourné chez lui 9 jours après son admission, et ce, sans souffrir de séquelles neurologiques. Seront passés en revue l'historique, les indications et le rôle de plus en plus grand de I'OEOM dans diverses affections, dont l'arrêt cardiaque.

Keywords: cardiac arrest, cardiac bypass, critical care, emergency medicine, extracorporeal membrane oxygenation (ECMO), resuscitation

Extracorporeal membrane oxygenation (ECMO) was derived from cardiopulmonary bypass and first instituted in the 1970s for the temporary cardiac and respiratory support of critically ill patients. ${ }^{1}$ Although initially used in the pediatric setting, in recent years, ECMO has been increasingly applied in settings that include emergency departments (EDs) for select adults with cardiorespiratory failure unresponsive to conventional management from a wide range of conditions. We present a dramatic case involving complete

From the *Department of Emergency Medicine, and the Divisions of Critical Care Medicine, $¥$ Cardiology, and §Cardiac Surgery, University of British Columbia, Vancouver, BC.

Correspondence to: Dr. Riyad B. Abu-Laban, Department of Emergency Medicine, Vancouver General Hospital, 855 West 12th Avenue, Vancouver, BC V5Z 1M9; abulaban@mail.ubc.ca.

This article has been peer reviewed.

(c) Canadian Association of Emergency Physicians 
recovery of a 29-year-old man placed on venoarterial (VA) ECMO for cardiogenic shock and respiratory failure following collapse and protracted ventricular fibrillation cardiac arrest in our ED. The history, indications, and increasing role of ECMO in a range of conditions, including cardiac arrest, are reviewed.

\section{CASE REPORT}

A 29-year-old man presented to the ED of Vancouver General Hospital, a level 1 trauma centre and tertiary teaching hospital, with a 2-day history of vague chest pain and dyspnea. He had played tennis that day and had no fever, cough, recent injury or travel, or recreational drug use. He was previously healthy and taking no medications.

At triage, he was pale, alert, and afebrile. His heart rate was 92 beats/min, with a respiratory rate of 32 breaths/ min, blood pressure of 152/83 $\mathrm{mm} \mathrm{Hg}$, and oxygen saturation of $99 \%$. Approximately 3 minutes after being triaged and placed on a stretcher, he was noted to be unresponsive and seizing. He was immediately brought into the ED and found to be pulseless and apneic. Cardiopulmonary resuscitation (CPR) was commenced. His initial cardiac rhythm was coarse ventricular fibrillation, and he was defibrillated with biphasic energy at $200 \mathrm{~J}$; however, ventricular fibrillation persisted.

A prolonged period of CPR and advanced cardiac life support resuscitation followed, during which the patient's rhythm alternated between ventricular fibrillation, ventricular tachycardia, pulseless electrical activity, and very brief periods of a perfusing narrow-complex rhythm. During this time, he was endotracheally intubated, defibrillated 11 times, and administered a total of $7 \mathrm{mg}$ of epinephrine, $300 \mathrm{mg}$ of amiodarone, $2 \mathrm{~g}$ of magnesium sulphate, $1 \mathrm{mg}$ of atropine, 3 ampoules of sodium bicarbonate, $1 \mathrm{~g}$ of calcium gluconate, and $100 \mathrm{mg}$ of lidocaine.

Because of the chest pain history and presence of ST elevation on the cardiac monitor during periods of perfusion, an acute coronary occlusion was suspected. Pulmonary embolism was also considered a possibility. During CPR, the patient's end-tidal $\mathrm{CO}_{2}$ level was reassuringly high and peaked at $30 \mathrm{~mm} \mathrm{Hg}$. The decision was made to administer $50 \mathrm{mg}$ IV of tenecteplase while CPR was ongoing after discussion with the on-call interventional cardiologist.

Seventeen minutes after thrombolytic administration, and after 49 minutes of virtually continuous
CPR, return of spontaneous circulation was achieved with a heart rate of 82 beats $/ \mathrm{min}$, blood pressure of $102 / 37 \mathrm{~mm} \mathrm{Hg}$, and oxygen saturation of $93 \%$. An electrocardiogram (ECG) showed marked anterolateral ST segment elevation, and the cardiac catheterization laboratory was activated. The patient remained hypotensive despite a peripheral dopamine infusion, and chest radiography revealed florid pulmonary edema. He was administered $100 \mathrm{mg}$ of intravenous furosemide and oral loading doses of acetylsalicylic acid (ASA) and clopidogrel. A femoral triple-lumen central venous catheter was inserted, and norepinephrine and heparin infusions were commenced.

At cardiac cathetherization, a subtotal occlusion of the mid-left anterior descending artery with Thrombolysis In Myocardial Infarction (TIMI)-2 flow from dissection and intracoronary thrombus was found. Placement of a bare metal stent resulted in TIMI-3 flow. An intra-aortic balloon pump (IABP) was placed; however, despite this and infusions of norepinephrine, dopamine, and milrinone, the patient remained hypotensive. An echocardiogram showed that the left ventricular ejection fraction (LVEF) was under $20 \%$. At this point, the patient's oxygen saturation was $80 \%$ on $100 \%$ fraction of inspired oxygen $\left(\mathrm{FiO}_{2}\right)$. An arterial blood gas revealed the following: $\mathrm{pH} 7.00$, oxygen partial pressure $\left(\mathrm{Po}_{2}\right) 40 \mathrm{~mm} \mathrm{Hg}$, and carbon dioxide partial pressure $\left(\mathrm{PcO}_{2}\right) 70 \mathrm{~mm} \mathrm{Hg}$.

The decision was made to initiate extracorporeal life support. Following angiography, percutaneous cannulas were placed in the right femoral artery and vein under fluoroscopic guidance and VA ECMO was commenced. Lung-protective ventilation, paralysis, and sedation were maintained. The patient was transferred to the intensive care unit and cooled to $34^{\circ} \mathrm{C}\left(93.2^{\circ} \mathrm{F}\right)$ for 24 hours. His norepinephrine requirements remained high; vasopressin was commenced, and $100 \mathrm{mg}$ of hydrocortisone was administered. The IABP and milrinone were initially continued to support his native cardiac output; however, they were determined to worsen the hypoxia, so both were weaned and the IABP was removed after approximately 24 hours. Following the period of therapeutic hypothermia, the patient was opening his eyes and obeying commands. One day later, a repeat echocardiogram found that his LVEF had improved to $50 \%$, so the ECMO was weaned and discontinued. Over the subsequent day, all remaining vasopressors and inotropes were weaned and discontinued. The patient was extubated 4 days after his ED presentation. 
During his hospital course, the patient received a total of 12 units of blood, 1 unit of platelets, and 1 unit of plasma. A fistula between the common femoral artery and great saphenous vein was found and managed conservatively. The patient was discharged home 9 days after his ED presentation, hemodynamically stable and neurologically normal. On telephone follow-up a few days after discharge, he told the lead author that he felt "a little beat up, you know, kind of like how you feel after a hard day of snowboarding."

\section{DISCUSSION}

Although the case we present is dramatic, neurologically normal survival after protracted cardiac arrest, frequently involving thrombolytic administration during CPR, has been reported previously. ${ }^{2}$ It is impossible to know if the thrombolytic agent played a role in our patient's outcome; however, two randomized controlled trials have shown that thrombolysis during CPR is not beneficial in an undifferentiated population., ${ }^{3,4}$ What is noteworthy about our case is the use of ECMO and the probable role it played. Given his profound cardiogenic shock and respiratory failure despite percutaneous coronary intervention, inotropic support, and the use of IABP, it is virtually certain that our patient would have died without ECMO. It is important for emergency physicians to be aware of the expanding use of ECMO for potentially salvageable adult patients with cardiorespiratory failure from a variety of etiologies.

ECMO is a form of cardiopulmonary support that is increasingly portable and potentially available in the ED of tertiary care centres and even the prehospital setting (Figure 1). The development of membrane oxygenator heart-lung machines for open heart surgery dates to the 1950s. However, it was in the 1970s that prolonged life support was first successful. ${ }^{1}$ Since then, extracorporeal life support modalities such as ECMO have been applied in a range of situations.

The broad term ECMO is commonly used to describe both the venovenous (VV) and VA versions of ECMO. VV ECMO is indicated when only the pulmonary system requires support, such as in severe acute respiratory distress syndrome, and requires venous cannulation with a dual lumen catheter or two single-lumen catheters. ${ }^{5}$ VA ECMO requires the placement of both venous and arterial catheters and is indicated when both the cardiovascular and pulmonary

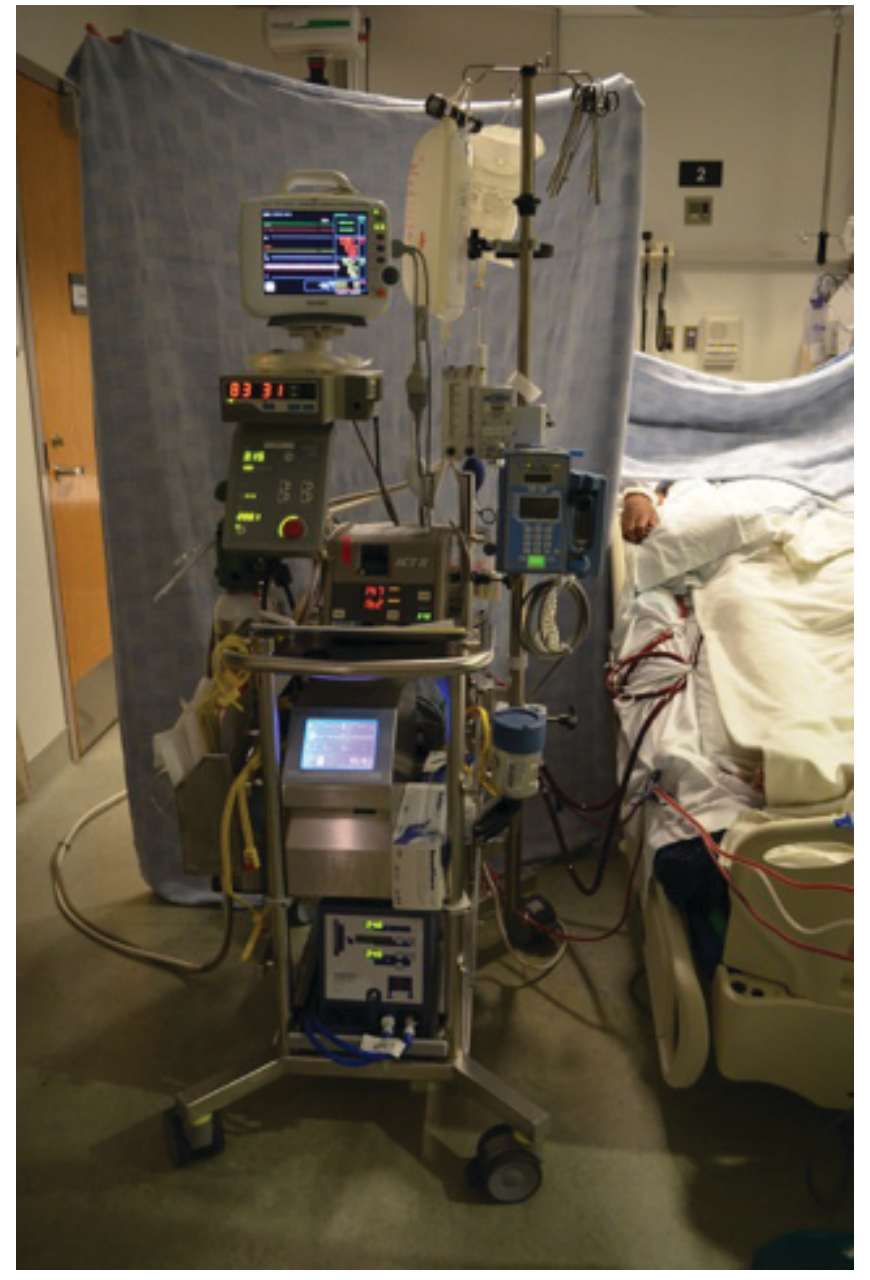

Figure 1. Venoarterial extracorporeal membrane oxygenation machine in use for an intensive care unit patient.

systems require support, such as in refractory ventricular fibrillation or fulminant myocarditis. ${ }^{6,7}$

VA ECMO involves the placement of two percutaneous large-bore vascular catheters, one arterial and one venous, typically both femoral in location, with the tip of the venous catheter at the inferior vena cava/atria junction and the tip of the arterial catheter in the common iliac artery. Venous blood is then pumped through an extracorporeal oxygenator and returned to the arterial circulation (Figure 2). ECMO machines involve some unique settings: the sweep gas flow rate influences $\mathrm{CO}_{2}$ removal, whereas the blood flow rate influences perfusion and oxygen delivery. Modern machines use a centrifugal pump, which results in less erythrocyte shear damage and flow that is preload dependent and afterload sensitive. Access pressures, which can indicate inflow resistance when excessively negative, must be monitored during ECMO. Less commonly, problems with blood return may also occur. 


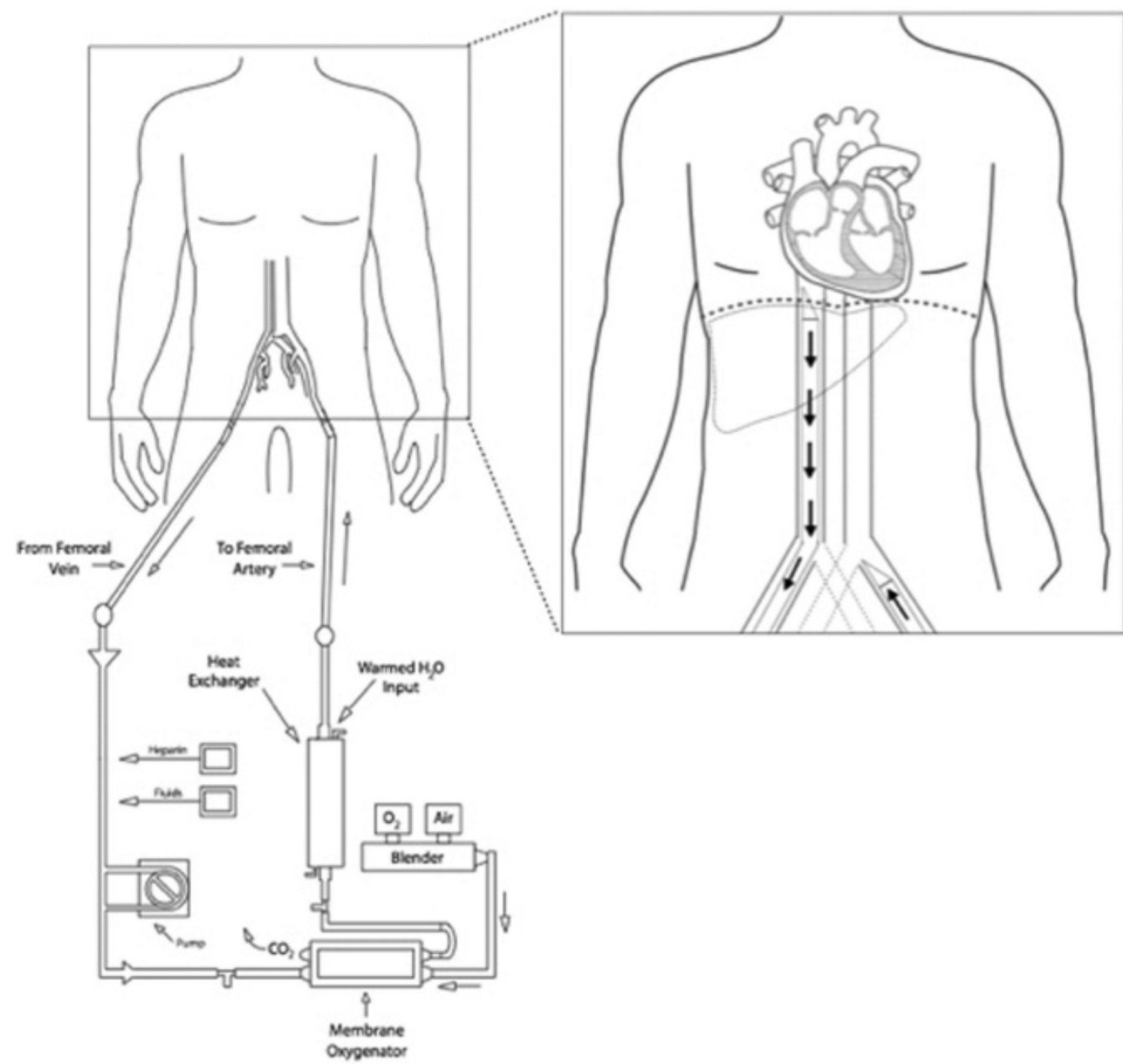

Figure 2. Schematic of extracorporeal membrane oxygenation circuit components and catheter placement (see the text for further details on the location of catheter tips).

Until recently, ECMO had been primarily used in the pediatric population, for conditions including neonates with respiratory failure and pulmonary hypertension and children with severe burns, traumatic hemorrhage, status asthmaticus, sepsis, or multisystem organ failure. ${ }^{8-10}$ Over the last decade, the use of ECMO has evolved and the indications for ECMO in adult patients have expanded. Extracorporeal cardiopulmonary resuscitation (ECPR) is a commonly used term describing the application of VA ECMO to cardiac arrest or post-cardiac arrest patients.
There remains a paucity of literature on this topic; however, recent retrospective reviews of ED-initiated ECPR quote survival rates ranging from 5 to $15.4 \%$ in patients who appeared to have a dismal prognosis. ${ }^{11}$

The use of ED ECMO remains poorly defined and fraught with anecdotal reports and local guidelines. It can be considered in any situation involving patients with potentially salvageable but otherwise likely fatal reversible respiratory and/or cardiac failure refractory to conventional management (Table 1). The best 


\begin{tabular}{l} 
Table 1. Potential indications for emergency department \\
ECMO \\
Cardiogenic shock refractory to conventional management \\
Acute myocardial infarction \\
Cardiac arrest or post-cardiac arrest \\
Fulminant myocarditis \\
Malignant arrhythmia \\
End-stage cardiomyopathy \\
Cardiotoxic ingestion (e.g., $\beta$-blockers, calcium channel \\
blockers, tricyclic antidepressants) \\
Ketoacidosis \\
Massive pulmonary embolism \\
Hemorrhagic shock \\
Bridging prior to heart transplantation \\
Cardiac or major vessel trauma \\
Massive pulmonary hemorrhage \\
Pulmonary trauma \\
Anaphylactic shock \\
Pulmonary failure refractory to conventional management \\
Status asthmaticus \\
Transfusion acute lung injury \\
Airway obstruction \\
Pneumonia \\
Acute graft-versus-host disease \\
Toxic inhalation \\
Aspiration \\
Bridging prior to lung transplantation \\
Drowning \\
Acute respiratory distress syndrome \\
Mixed cardiopulmonary failure refractory to conventional \\
management \\
Severadrenergic crisis (e.g., pheochromocytoma) \\
\hline
\end{tabular}

outcomes for VA ECMO appear to be in inflammatory processes secondary to various infections, in particular myocarditis, where survival rates as high as $66 \%$ have been reported. ${ }^{7,12}$ The use of VA ECMO is also increasingly described for toxic ingestions resulting in intractable hemodynamic instability, as well as a range of other conditions. ${ }^{13-19}$ The role of ECMO in accidental hypothermia is particularly relevant to emergency medicine; a recent review in the New England fournal of Medicine advocated the use of ECMO in cardiac arrest caused by accidental hypothermia, even if this requires transport to another centre, in patients with a core temperature less than $32^{\circ} \mathrm{C}\left(89.6^{\circ} \mathrm{F}\right)$ and circumstances suggesting that cooling took place prior to the arrest. ${ }^{20}$

Dramatic survival following the use of VA ECMO during or following cardiac arrest, as occurred in our patient, has been reported..$^{6,11,21-24}$ A 2004
"Best-Evidence Topic Report" suggested that 15 to $25 \%$ of selected patients who suffer witnessed cardiac arrest and are unresponsive to traditional emergency cardiac care interventions may be successfully resuscitated with ECMO,${ }^{25}$ and two subsequently published studies have reported similar or higher survival rates. . $6,27^{2}$

Historically, the initiation of VA ECMO required advanced surgical training and an operating room environment. However, percutaneous Seldinger techniques have made ECMO technically easier to initiate in a range of settings provided that treating physicians are comfortable managing critically ill patients, appropriately trained, and aware of the complications and risks of this intervention. Increasingly, ECMO is now commenced in the ED, in some centres by emergency physicians. Regardless of where ECMO is commenced, the large-bore catheters required should ideally be inserted under fluoroscopic or transesophageal echocardiographic guidance to ensure proper placement and prevent damage to major vascular structures, which can result in rapid and uncontrollable exsanguination. Additional complications include lower extremity ischemia or compartment syndrome (sometimes requiring fasciotomy or amputation), stroke, renal failure, and infection. Placement of the large arterial sheaths required typically involves a preprocedural angiogram when done in a cardiac catherization laboratory, as occurred in our case; this is advisable given the extra-stiff guidewires and multiple dilatations required. However, advanced imaging modalities are frequently not employed when they are unfeasible, and the risk of blind placement, or placement facilitated only by ultrasonography, is deemed to be outweighed by the potential benefits of the intervention. Such is typically the case in the ED with patients in cardiac arrest or expected to rapidly die without further intervention. Some sites, such as the Sharp Memorial Hospital in San Diego, have developed specific inclusion and exclusion criteria for emergency physician-initiated ED ECMO using ultrasound guidance. ${ }^{28}$ ECMO has also been used in the prehospital setting, particularly in Europe, for both interhospital transport and mobile medical units. ${ }^{29-32}$ However, the role, if any, of prehospital ECMO remains poorly defined. Further research is required to better clarify the role, patient eligibility criteria, and outcomes of ECMO, and a recently established registry may be helpful in this regard. ${ }^{12}$ 


\section{CONCLUSION}

Our dramatic case illustrates the potential role of ECMO in emergency medicine and critical care. Emergency physicians should be aware of the increasing use of ECMO in potentially salvageable adult patients with cardiorespiratory failure from a variety of etiologies and consider the early initiation of this therapy in appropriate patients, either within their institution or through transport to another centre.

Acknowledgements: We acknowledge the outstanding care provided to our patient, from the moment of his triage through to his discharge, by the staff of the Vancouver General Hospital emergency department, cardiac catheterization laboratory, perfusion services, and intensive care unit. We also thank Mr. Brian Baxter for developing Figure 2.

Competing interests: None declared.

\section{REFERENCES}

1. Mattox KL, Beall AC. Resuscitation of the moribund patient using portable cardiopulmonary bypass. Ann Thorac Surg 1976;22:436-42, doi:10.1016/S0003-4975(10)64452-9.

2. Clark K, Abu-Laban RB, Zed PJ, et al. Neurologically normal survival after fibrinolysis during prolonged cardiac arrest: case report and discussion. CFEM 2003;5:49-53.

3. Abu-Laban RB, Christenson JM, Innes GD, et al. Tissue plasminogen activator in cardiac arrest with pulseless electrical activity. $N$ Engl $f$ Med 2002;346:1522-8, doi: 10.1056/NEJMoa012885.

4. Böttiger BW, Arntz H-R, Chamberlain DA, et al. Thrombolysis during resuscitation for out-of-hospital cardiac arrest. N Engl 7 Med 2008;359:2651-62, doi:10.1056/ NEJMoa070570.

5. Brodie D, Bacchetta $M$. Extracorporeal membrane oxygenation for ARDS in adults. N Engl 7 Med 2011;365:1905-14, doi:10.1056/NEJMct1103720.

6. Chiu C-C, Chiu C-W, Chen Y-C, et al. Cardiac arrest with refractory ventricular fibrillation: a successful resuscitation using extracorporeal membrane oxygenation. Am 7 Emerg Med 2013;31:264.e1-2.

7. Yamamoto LG, Young LL. Acute-onset dysrhythmia heralding fulminant myocarditis and refractory cardiac arrest treated with ED cardiopulmonary bypass and extracorporeal membrane oxygenation. Am 7 Emerg Med 2007;25:348-52, doi:10.1016/j.ajem.2006.05.028.

8. Posner JC, Osterhoudt KC, Mollen CJ, et al. Extracorporeal membrane oxygenation as a resuscitative measure in the pediatric emergency department. Pediatr Emerg Care 2000; 16:413-5, doi:10.1097/00006565-200012000-00008.

9. Fiser RT, Morris MC. Extracorporeal cardiopulmonary resuscitation in refractory pediatric cardiac arrest. Pediatr Clin North Am 2008;55:929-41, doi:10.1016/j.pcl.2008.04.003.

10. Maclaren G, Butt W, Best D, et al. Extracorporeal membrane oxygenation for refractory septic shock in children: one institution's experience. Pediatr Crit Care Med 2007;8:447-51, doi:10.1097/01.PCC.0000282155.25974.8F.

11. Shinar Z, Bellezzo JM, Paradis N, et al. Emergency department initiation of cardiopulmonary bypass: a case report and review of the literature. 7 Emerg Med 2012;43:836, doi:10.1016/j.jemermed.2011.06.134.

12. Paden ML, Conrad SA, Rycus PT, et al. Extracorporeal Life Support Organization Registry report 2012. ASAIO 72013 ; 59:202-10, doi:10.1097/MAT.0b013e3182904a52.

13. Maclaren G, Butt $W$, Cameron $P$, et al. Treatment of polypharmacy overdose with multimodality extracorporeal life support. Anaesth Intensive Care 2005;33:120-3.

14. Sojod G, Diana M, Wall J, et al. Successful extracorporeal membrane oxygenation treatment for pheochromocytomainduced acute cardiac failure. Am 7 Emerg Med 2012;30: 1017.e1-3, doi:10.1016/j.ajem.2011.05.006.

15. Hifumi T, Kiriu N, Kato H, et al. Survival after prolonged resuscitation from cardiac arrest due to diabetic ketoacidosis using extracorporeal life support. Am 7 Emerg Med 2013;31: 892.e1-2.

16. Kuroda H, Masuda Y, Imaizumi H, et al. Successful extracorporeal membranous oxygenation for a patient with life-threatening transfusion-related acute lung injury. 7 Anesth 2009;23:424-6, doi:10.1007/s00540-009-0760-5.

17. Kukita I, Okamoto K, Sato T, et al. Emergency extracorporeal life support for patients with near-fatal status asthmaticus. Am $\mathcal{F}$ Emerg Med 1997;15:566-9, doi:10.1016/ S0735-6757(97)90158-3.

18. Huang S-C, Wu E-T, Chen Y-S, et al. Extracorporeal membrane oxygenation rescue for cardiopulmonary resuscitation in pediatric patients. Crit Care Med 2008;36:1607-13, doi:10.1097/CCM.0b013e318170b82b.

19. Arlt M, Philipp A, Voelkel S, et al. Extracorporeal membrane oxygenation in severe trauma patients with bleeding shock. Resuscitation 2010;81:804-9, doi:10.1016/ j.resuscitation.2010.02.020.

20. Brown DJA, Brugger H, Boyd J, et al. Accidental hypothermia. N Engl 7 Med 2012;367:1930-8, doi:10.1056/ NEJMra1114208.

21. Shin J-S, Lee S-W, Han G-S, et al. Successful extracorporeal life support in cardiac arrest with recurrent ventricular fibrillation unresponsive to standard cardiopulmonary resuscitation. Resuscitation 2007;73:309-13, doi:10.1016/j. resuscitation.2006.09.011.

22. Brunner M-E, Siegenthaler N, Shah D, et al. Extracorporeal membrane oxygenation support as bridge to recovery in a patient with electrical storm related cardiogenic shock. Am 7 Emerg Med 2013;31:467.e1-6, doi:10.1016/j.ajem.2012. $\underline{08.043}$.

23. Cohen MI, Gaynor JW, Ramesh V, et al. Extracorporeal membrane oxygenation for patients with refractory ventricular arrhythmias. 7 Thorac Cardiovasc Surg 1999;118:961-3, doi:10.1016/S0022-5223(99)70072-3.

24. Brown DFM, Jaffer FA, Baker JN, et al. Case records of the Massachusetts General Hospital. Case 28-2013. A 52year-old man with cardiac arrest after an acute myocardial infarction. N Engl 7 Med 2013;369:1047-54, doi:10.1056/ NEJMcpc1304164.

25. Dunning J, Levine A. Best evidence topic report. Cardiopulmonary bypass and the survival of patients in 
cardiac arrest. Emerg Med 7 2004;21:499-501, doi:10.1136/ emj.2004.016543.

26. Avalli L, Maggioni E, Formica F, et al. Favourable survival of in-hospital compared to out-of-hospital refractory cardiac arrest patients treated with extracorporeal membrane oxygenation: an Italian tertiary care centre experience. Resuscitation 2012;83:579-83, doi:10.1016/j.resuscitation.2011.10.013.

27. Haneya A, Philipp A, Diez C, et al. A 5-year experience with cardiopulmonary resuscitation using extracorporeal life support in non-postcardiotomy patients with cardiac arrest. Resuscitation 2012;83:1331-7, doi:10.1016/j.resuscitation.2012.07.009.

28. Bellezzo JM, Shinar Z, Davis DP, et al. Emergency physician-initiated extracorporeal cardiopulmonary resuscitation. Resuscitation 2012;83:966-70, doi:10.1016/j.resuscita tion.2012.01.027.
29. Jones C, Hommers C, Burns B, et al. ECMO retrieval in NSW and beyond. Curr Anaesth Crit Care 2010;21:282-6, doi:10.1016/j.cacc.2010.07.004.

30. Foley DS, Pranikoff T, Younger JG, et al. A review of 100 patients transported on extracorporeal life support. ASAIO 7 2002;48:612-9, doi:10.1097/00002480-20021100000007.

31. Lebreton G, Pozzi M, Luyt C-E, et al. Out-of-hospital extra-corporeal life support implantation during refractory cardiac arrest in a half-marathon runner. Resuscitation 2011; 82:1239-42, doi:10.1016/j.resuscitation.2011.04.002.

32. Arlt M, Philipp A, Voelkel S, et al. Early experiences with miniaturized extracorporeal life-support in the catheterization laboratory. Eur 7 Cardiothorac Surg 2012;42:858-63, doi:10.1093/ejcts/ezs176. 